\title{
Experiences of Screening for Abdominal Aortic Aneurysm-In and Out on Five Minutes
}

\author{
Monica Petterssonn ${ }^{1,2}$, Birgitta Gedda ${ }^{3}$, Ina Berndsson ${ }^{4}$ \\ ${ }^{1}$ Department of Vascular Surgery, Sahlgrenska University Hospital, Gothenburg, Sweden \\ ${ }^{2}$ Institute of Health and Care Sciences, Sahlgrenska Academy, University of Gothenburg, Gothenburg, Sweden \\ ${ }^{3}$ Research and Development Unit, Primary Health Care Fyrbodal, Vänersborg, Sweden \\ ${ }^{4}$ Institute of Nursing, Health and Culture, University West, Trollhättan, Sweden \\ Email: ${ }^{\text {monica.e.pettersson@vgregion.se }}$
}

Received 30 April 2014; revised 31 May 2014; accepted 7 June 2014

Copyright (C) 2014 by authors and Scientific Research Publishing Inc.

This work is licensed under the Creative Commons Attribution International License (CC BY).

http://creativecommons.org/licenses/by/4.0/

(c) (i) Open Access

\section{Abstract}

Background: The purpose of AAA screening is to prevent rupture and mortality. Screening for life-threatening diseases is a double-edged sword. The aim of this study is to describe 65-year-old men's experiences of health related quality of life and anxiety after screening for Abdominal Aortic Aneurysm, and experiences of information and reasons for not participating. Methods: 368 men answered Short Form 36 (SF-36), and anxiety and depression scale (HAD). 72 telephone interviews were conducted with the participants and 77 with those who declined to take part in the screening programme. Results: The SF-36 domains of Physical Function and Role limitations due to emotional health problems were significantly better for men who had undergone screening compared to a matched population. Compared to non-smokers, smokers had lower values in the SF-36 domains of general health perceptions, social functioning, role limitations due to emotional health problems and mental health. $80 \%$ of patients did not experience any form of anxiety/panic in connection with the screening invitation. Of the men who did not participate, $56 \%$ stated that they would like to be screened or had already undergone the examination. Conclusion: The men who underwent the investigation were healthier in some of the SF-36 domains than the general population. The participants did not experience any great anxiety before the screening and despite the short duration of the examination.

\section{Keywords}

Abdominal Aortic Aneurysm, Nursing, Screening, Prevention

\footnotetext{
*Corresponding author.
} 


\section{Introduction}

The aim of screening is to diagnose diseases before symptoms appear. Abdominal Aortic Aneurysm (AAA) is usually asymptomatic until rupture occurs but can be discovered during a physical examination for other conditions. Overall mortality due to ruptured AAA is about $80 \%$ in the western world [1]. The purpose of AAA screening is to prevent rupture and mortality. However, screening for life-threatening diseases is a double-edged sword. Potentially it can result in beneficial effects, as in some cases early detection leads to better prognosis and less aggressive treatment [2]. Men who know that they are at increased risk of dying of heart disease may be more inclined to take other risks. Although screening is a cheap and fast procedure we are not fully aware of all its social and psychological costs [3].

Screening is performed for a number of diagnoses such as breast, prostate and colorectal cancer as well as AAA [4]-[6]. Independent predictors of participation in AAA screening was younger age (65 - 67 years), high social class, being married, a short distance to travel $(<20 \mathrm{~min})$ and cardiovascular or pulmonary disease [7]. Scott et al. [8] revealed that screening reduces mortality in men but did not observe any decrease in women.

Before screening, an information letter is sent to potential participants. The information must be balanced between the benefits and negative effects of screening or subsequent management, which include morbidity and mortality, detection of a disease that would not have presented during the person's life time and psychosocial problems. Not all participants want to make a decision about screening, which highlights the relationship between such a decision (intention) and subsequent screening behaviour. Individuals who receive more information about the risks involved often participate in screening to a greater extent, although the opposite can also be the case [9] [10].

\section{Background}

The absolute risk of mortality from AAA was 3.3 per thousand (0.33) in a control group and 1.9 per thousand in an intervention group [11] [12]. AAA screening results have been published in several international studies [6] [11] [13]-[15]. Wanhainen et al. [16] found no significant differences in self-reported quality of life prior to screening among patients diagnosed with AAA compared with those not diagnosed. However, patients who already had poor quality of life prior to screening experienced a further deterioration after receiving the diagnosis. Another study revealed that participants in a screening programme were healthier than the general population [17]. Patients diagnosed with an AAA by means of screening but who did not undergo surgery scored 5\% lower in Health related quality of life (HRQoL) and health compared to controls [18].

Knowledge of invisible changes that are normally neither felt nor experienced and only detectable by medical technologies influences and changes people's perceptions about themselves and their bodies, as described in the case of osteoporosis, hypertension and cholesterol [19] [20]. Most men with aneurysms also suffer from other cardio-vascular or chronic obstructive pulmonary diseases [21]. HRQoL in patients suffering from cardiovascular disease may be affected by smoking, high body mass index (BMI) and other comorbidities, especially diabetes. In comparison with the corresponding group in the general population, individuals suffering from cardiovascular disease reported more pain, discomfort and anxiety [22]. Information about the screening programme such as benefits and risks should be easy to understand. The participants have to make an individual choice based on the information provided. The aim of this study is to describe 65-year-old men's experiences of health related quality of life and anxiety after screening for Abdominal Aortic Aneurysm, and experiences of information and reasons for not participating.

\section{Methods}

\subsection{Theoretical Framework-AAA Screening from a National Health Care Perspective}

Screening of 65-year-old men is one of the many preventive interventions that take place in Swedish national health care as in many other western countries.

Disease prevention work in Sweden aims to protect and improve the health of as many inhabitants as possible. In this study, risk factors are specific health problems. The strategies used to prevent them can be systematically analysed on the basis of the risk posed by the disease in question, cost effectiveness and the degree of available evidence [23]. As part of this work, a national screening programme has been implemented, aimed at a number 
of different individuals and groups with increased vulnerability to disease or illness. National screening refers to a population-based programme for the healthy population, where the health care system assumes responsibility for following up the effects of screening [24].

\subsection{Design and Sample}

All men who reached the age of 65 years $(n=10,361)$ in 2009 were invited to participate in an ultrasound screening examination of the abdominal aorta, performed by paramedical personnel in five screening centres in the west of Sweden. Of these, 14.5\% declined participation. 65 years is the retirement age in Sweden.

An explorative quantitative design was used in which HRQoL was measured by the Short Form 36 (SF-36) instrument, anxiety and depression by the hospital anxiety and depression scale (HAD), while a descriptive design was employed in telephone interviews with specific questions. The questionnaire was distributed before and the interview conducted 7 - 14 days after screening. The participants were selected consecutively.

For the HRQoL measurement, a reference sample, age and gender-matched to the participants, was randomly drawn from the Swedish SF-36 v2.0 national normative database $(n=2185)$ for comparison with the present group [25].

Study Group 1: Questionnaire.

During the study period (14th-30th September, 2009), 516 men who had undergone AAA screening were consecutively invited to participate and answer questions about HRQoL, anxiety and depression on reaching their 65th year.

Study Group 2: Telephone interviews.

One group comprising 72 participants who had undergone screening during the previous week answered questions about the screening procedure.

Study Group 3: Telephone interviews.

A third group of 77 men who had been invited to undergo screening but failed to appear and did not bother to cancel their appointments were asked why they did not wish to participate.

\subsection{Data Collection}

The Short Form-36 (SF-36) is a HRQoL instrument developed by Ware and Shelbourne [26] to measure physical and mental health. The SF-36 has been standardised within the quality of life assessment framework. HRQoL was evaluated using the Swedish version of the SF-36 Health Survey version 2.0 [27]. The instrument comprises 36 items that assess eight areas of health: Physical functioning (PF), role limitations due to physical health problems (RP), bodily pain (BP), social functioning (SF), vitality (VT), mental health (MH), role limitations due to emotional health problems (RE) and general health perceptions (GH). Scores are coded for each area. The total is calculated and transformed to a scale ranging from 0 - 100. A total score of 100 indicates the best possible state of health. SF-36 has been tested for both internal and external validity as well as reliability [28].

The participants also rated their anxiety and depression by means of the HAD (Hospital Anxiety and Depression) [29], which is used for psychiatric morbidity screening in patients with somatic problems. The questionnaire comprises 14 questions and has two sub-scales, one of which measures depression (7 questions) and the other anxiety (7 questions). The sub-scale scores range from 0 to 21 (where 21 indicate serious problems, i.e., depression or anxiety).

Men who had undergone screening were asked structured questions about the cost (approx.12 €), information in the invitation letter and whether the interval from receiving the invitation to the screening was optimal. Additional questions were whether they had had previous experience of AAA, the time it took them to travel to the examination, if it had been difficult to find a parking space, their impression of the examination room and how long they had to wait. Questions were also posed about the examination, their opinion of staff and the information they received about the results.

The men who failed to attend were asked an open-ended question about whether they had intended to participate and why they did not do so.

\subsection{Procedure}

A letter was sent to the potential participants containing details of when and where the screening would be car- 
ried out, the procedure and information about the disease. For the investigation the participants only needed to pull up their shirt and lie on an examination table. Gel for the ultrasound probe was spread over the upper abdomen. An image of the aorta was available immediately on a screen, and the participants were informed at once whether or not it was enlarged. The procedure only took five minutes.

\subsection{Data Analysis}

Descriptive data were reported as means \pm standard deviations or median values with ranges and presented in a histogram. A sample t-test was used to compare the SF-36 sub-scale scores with normative data (SPSS 11.0 for Windows software). $\mathrm{p}<0.05$ was considered statistically significant. When calculating the differences between the study group and the age and gender-matched reference sample, the level of significance was reduced to $\mathrm{p}<$ 0.001. The interviews with those who chose not to participate in the screening are only presented in percent.

\subsection{Ethical Considerations}

All patients were thoroughly informed about the purpose of the study and their right to withdraw at any time. The Nursing Code of Ethics (2000) was used as a basis for the ethical considerations. The Regional Ethical Review Board in Gothenburg (S 40308) approved the study [30].

\section{Results}

The questionnaire was completed by 368 men (71.3\%), while eight declined or returned unanswered questionnaires. The reason for declining to participate in the screening was illness or being abroad. Mean time for the one-way journey to the screening unit was 36.6 minutes (range 1 - 180 minutes) (SD 23.44). A total of 48 men (9.3\%) did not participate in the screening examination, cancelled or rescheduled their appointment. Of the men who attended the screening, 28 (6\%) were aged under 65, while the corresponding figure for those who declined participation was 27 (55). Of the respondents, 57 (16\%) indicated that they smoked. Half of the men (172, 51.3\%) had symptoms that hindered them in daily life. All background factors are presented in Table 1.

\subsection{Health-Related Quality of Life (HRQoL)}

HRQoL (SF36) was significantly improved in men who had attended the screening examination compared to the general population (Figure 1) in the domains of physical functioning (PF) $\mathrm{p}<0.0000$ and role limitations due to emotional health problems (RE) $\mathrm{p}=0.0003$. Statistical differences were not evident in role limitations due to physical health problems $(\mathrm{RP}) \mathrm{p}=0.0021$, bodily pain $(\mathrm{BP}) \mathrm{p}=0.0384$, general health perceptions $(\mathrm{GH}) \mathrm{p}=$ 0.0761 , vitality $(\mathrm{VT}) \mathrm{p}=0.0236$, social functioning $(\mathrm{SF}) \mathrm{p}=0.0019$ and mental health $(\mathrm{MH}) \mathrm{p}=0.0397$. Statistical differences were seen in all HRQoL domains ( $p>0.0001)$ in those who had symptoms compared with those who did not report any symptoms. Persons who smoked had a lower score in some of the SF-36 domains compared to non-smokers, see Figure 2. p-values for the SF-36 domains were as follows; physical functioning $(\mathrm{PF}) \mathrm{p}=0.047$, role limitations due to physical health problems $(\mathrm{RP}) \mathrm{p}=0.149$, bodily pain $(\mathrm{BP}) \mathrm{p}=0.19$, general health perceptions $(\mathrm{GH}) \mathrm{p}=0.042$, vitality $(\mathrm{VT}) \mathrm{p}=0.169$, social functioning $(\mathrm{SF}) \mathrm{p}=0.001$, role limitations due to emotional health problems $(\mathrm{RE}) \mathrm{p}=0.001$ and mental health $(\mathrm{MH}) \mathrm{p}=0.001$.

\subsection{HAD-Score}

Mean values and standard deviations for HAD scores on the two scales that measure anxiety and depression are presented in Table 2 and Table 3.

The results revealed that of those examined, 19 (5\%) exhibited possible anxiety and 17 (5\%) had probable psychiatric morbidity, while the corresponding figures for depression were possible depression 21 (6\%) and probable depression 13 (4\%). Of these, 7 (2\%) had high scores on both the anxiety and the depression scales. Five people stated that they suffered from depression.

294 (80\%) did not experience any form of panic/anxiety in relation to the screening and about 272 (70\%) were not afraid that something negative would happen. To the question "I feel as if I am slowed down" on the depression scale, 145 (40\%) answered "sometimes". All responses to the various items on the anxiety and depression scales are presented in Figure 3 and Figure 4. 
Table 1. Background factors of the study population in the present study $(n=368)$ in percent.

\begin{tabular}{lcc}
\hline Background factors & Percent \\
\hline Employed & 32 \\
Worked full time & 16 \\
Had a partner & 86 \\
Contact with relatives & 90 \\
Contact with their children & 86 \\
No problem with health & 36 \\
Hypertension & 14 \\
Cardiovascular disease & 10 \\
Pulmonary disease & 3 \\
Diabetes & 8 \\
Cancer & 1 \\
Depression & 2 \\
Mustrointestinal problems & 4 \\
\hline
\end{tabular}

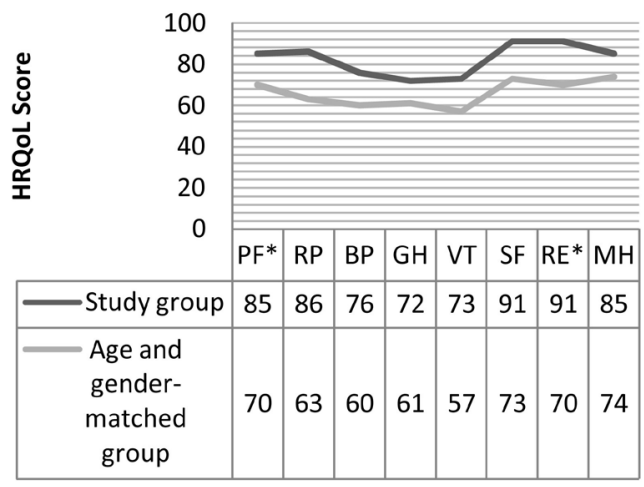

Figure 1. HRQoL, Short Form-36 (SF-36) mean scores of the study group $(n=368)$ compared with an age and gender matched sample drawn from the Swedish SF-36 general population database $(\mathrm{n}=11)$. $\mathrm{PF}=$ Physical functioning; $\mathrm{RP}=$ role-physical; $\mathrm{BP}=$ bodily pain; $\mathrm{GH}$ = general health; $\mathrm{VT}=$ vitality; $\mathrm{SF}=$ social functioning; $\mathrm{RE}=$ role-emotional; $\mathrm{MH}=$ mental health in mean. * indicates a significant difference between the study group and the reference sample; The scores range from 0 - 100, with a higher score indicating a higher level of distress or impairment.

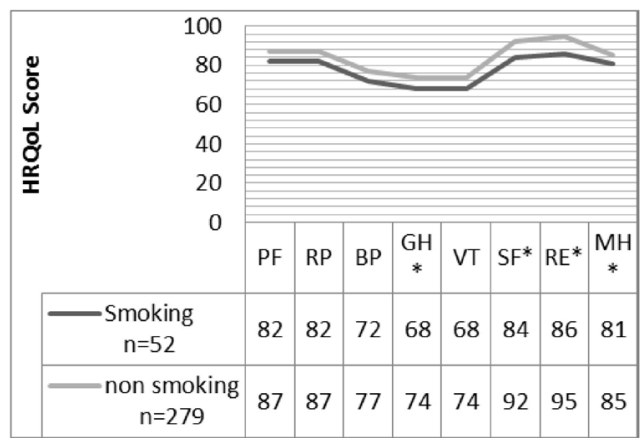

Figure 2. Health-related quality of life, Short Form-36 (SF-36) mean scores of persons who smoke $(\mathrm{n}=52)$ and nonsmokers $(\mathrm{n}=279)$. $\mathrm{PF}=$ Physical functioning; $\mathrm{RP}=$ role-physical; $\mathrm{BP}=$ bodily pain; $\mathrm{GH}$ = general health; $\mathrm{VT}=$ vitality; $\mathrm{SF}$ $=$ social functioning; $\mathrm{RE}=$ role-emotional; $\mathrm{MH}=$ mental health in mean. ${ }^{*}$ indicates a significant difference between the study group and the reference sample. The scores range from 0 - 100, with a higher score indicating a higher level of distress or impairment. 
Table 2. Mean and Std. Deviation for questionnaire that related to anxiety.

\begin{tabular}{cccc}
\hline Questionnaire That Relate to Anxiety & $\mathrm{n}=$ & Mean & Std. Deviation \\
\hline I feel tense or wound up. & 366 & 0.4044 & 0.62844 \\
I get a sort of frightened feeling as if something bad is about to happen. & 367 & 0.3488 & 0.65985 \\
Worrying thoughts go through my mind. & 366 & 0.3962 & 0.64861 \\
I can sit at ease and fell relaxed. & 366 & 0.6011 & 0.70567 \\
I get a sort of frightened feeling like butterflies in the stomach. & 366 & 0.3579 & 0.55914 \\
I feel restless and have to be on the move. & 326 & 0.6687 & 0.77702 \\
I get sudden feelings of panic. & 358 & 0.1983 & 0.49343 \\
\hline
\end{tabular}

Table 3. Mean and Std. Deviation for questionnaire that related to Depression.

\begin{tabular}{|c|c|c|c|}
\hline Questionnaire That Relate to Depression & $\mathrm{n}=$ & Mean & Std. Deviation \\
\hline I still enjoy the things I used to enjoy. & 367 & 0.3297 & 0.55591 \\
\hline I can laugh and see the funny side of things. & 366 & 0.2541 & 0.53217 \\
\hline I feel cheerful. & 365 & 0.2795 & 0.59183 \\
\hline I feel as if I am slowed down. & 363 & 0.8650 & 0.89564 \\
\hline I have lost interest in my appearance. & 367 & 0.4905 & 0.76415 \\
\hline I look forward to enjoyment with things. & 357 & 0.4482 & 0.69163 \\
\hline I can enjoy a good book or radio or TV programme. & 358 & 0.3687 & 0.70478 \\
\hline
\end{tabular}

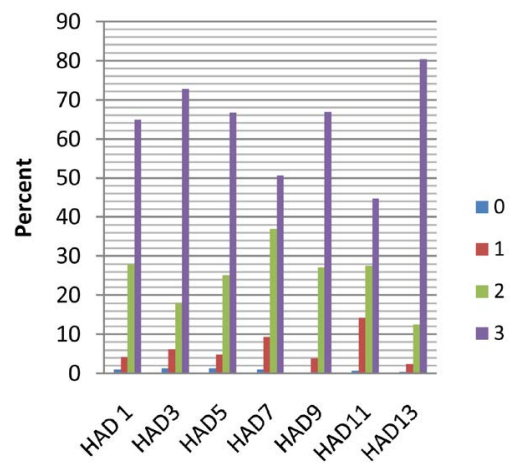

Axelrubrik

Score 0 - 3, where a score of 0 is optimal.

HAD 1: I feel tense or wound up.

HAD 3: I get a sort of frightened feeling as if something bad is about to happen.

HAD 5: Worrying thoughts go through my mind

Had 7: I can sit at ease and feel relaxed.

HAD 9: I get a sort of frightened feeling like butterflies in my stomach.

HAD 11: I feel restless and have to be on the move.

HAD 13: I get sudden feelings of panic/anxiety.

Figure 3. Anxiety scale (answers in percent).

\subsection{Telephone Interview-Group 2}

\subsubsection{Information}

Of the men who had taken part in the screening investigation, 67 (93\%) were satisfied with the written information received. The information was described as factual but a complaint was that they were not told that only a part of the upper body had to be screened. The men were expected to know how common AAA is and the normal size of the aorta. Eight (11\%) of the men already knew about AAA.

With the exception of three (4\%), all participants were satisfied with the interval between receipt of the letter 


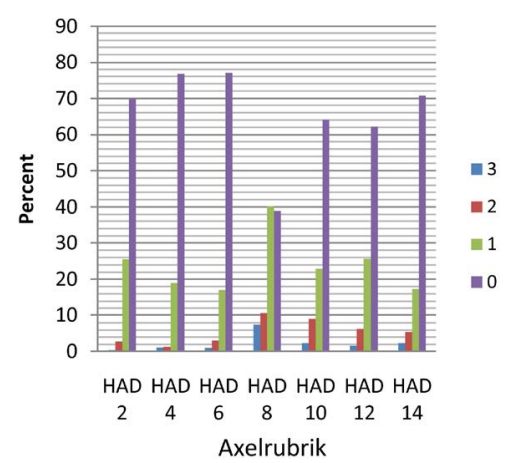

Score 0 - 3, where a score of 0 is optimal.

HAD 2: I still enjoy the things I used to enjoy.

HAD 4: I can laugh and see the funny side of things.

HAD 6: I feel cheerful.

HAD 8: I feel as if I am slowed down.

HAD 10: I have lost interest in my appearance.

HAD 12: I look forward to enjoyment with things.

HAD 14: I can enjoy a good book or radio or TV programme.

Figure 4. Depression scale (answers in percent).

inviting them to the investigation and the examination itself. Two months was considered too long and a week too short. The period in the waiting room could range from 0 - 35 minutes. Waiting for up to 15 minutes was considered acceptable, although $13(10 \%)$ men had to wait for more than 15 minutes.

\subsubsection{Screening Procedure}

The cost (approx.12€) of the screening did not constitute a problem for 289 (84\%) of the men. The five minute examination was conducted in a satisfactory manner, as they reported experiencing no feeling of stress, that staff members answered their questions and allowed them time to talk. One of the men complained that staff members' behaviour was unsatisfactory as despite his mobility problems they berated him for not getting up on the examination table quickly enough.

Information about the results was described as satisfactory by $63(88 \%)$ of the participants. Those who were unhappy with the information provided would have preferred to see the image themselves and wanted the staff to communicate the results directly from the measurements on the screen. Several of the men wanted detailed results, the most common being the measurements of the aorta. Some were not aware of the normal values. Someone said "I did not understand what 14 meant, but it was good to get the piece of paper (with the result) to bring home". Others did not remember what was said but read the information letter. Two (2.5\%) of the men who had values above the normal range felt that staff members provided satisfactory information and responded well to questions. However, in one case the results were highlighted in red, which seemed to cause distress. Both of these men received information about where and when follow up would take place on the same or the following day.

The telephone interviews revealed that both wives and children encouraged the men to undergo the examination.

\subsection{Telephone Interview-Group 3 (Reason for Not Participating in the Screening Procedure)}

Of the 77 men who did not participate, 43 (56\%) stated that they will go in the future or had previously undergone such an examination, 6 (8\%) were uncertain about the necessity of attending and 28 (36\%) did not wish to take part in the screening. The main reasons for not attending were that they had forgotten the time or been away for a longer or shorter period. Some had changed their appointment in order to undergo the examination closer to home or their workplace. During the interview, many availed of the opportunity to ask questions about the survey and AAA. 
The reasons stated by the 6 men (8\%) who were unsure whether or not they would be able to attend were: out of town, illness or transport problems. Of the 28 (36\%) who declined, most were not interested in or negative towards the investigation.

Transport was a problem for many either due to distance or no access to a car. Several had problems with the AAA (had to undergo regular examinations, treatment or had been in hospital) and had had no time to attend the screening or had already had an investigation of the aorta associated with the disease. Some men were physically or mentally disabled and their family members were unable to bring them to the examination. Others considered themselves healthy and not in need of AAA screening or believed that they would die of other causes.

\section{Discussion}

AAA screening is economical from a societal perspective, and in order to save life it is important to identify people with an enlarged aorta before it ruptures. However, the question is which people attend such screening and how they experience it.

The result of this study indicates that people who participated in AAA screening had significantly higher scores in physical functioning and role limitations due to emotional health problems than a reference population, which supports previous studies that healthier people participate in screening [17]. The interviews with those who failed to participate in the screening revealed that many suffered from illness and were unable to travel to a screening centre, which could explain the result. Another reason for not participating was that the person had already been screened in connection with other medical examinations and it was difficult to say whether or not it was due to illness. It was found that men who had disorders or health problems had significantly worse HRQoL than those who were symptom-free. In our interview study, two people were diagnosed with an enlarged AAA, which may have had an effect on the results. In their study, Wanhainen et al. [16], demonstrated that there was no difference in HRQoL between those diagnosed with AAA after screening and those who did not receive such a diagnosis. However, individual experiences and the impact on health and life can vary a great deal. Eriksson also addressed this issue, contending that the presence of illness and feeling ill may be entirely different and reflect two divergent views on health. Dimensions of health can be described both as subjective symptoms and as objective signs [31]. Patients undergoing screening can experience an impact on their health while waiting for the diagnosis, although in our study the participants in the screening programme had better health in most of the SF-36 domains compared to the general population. Previous studies have revealed that men reported anxiety as a consequence of unanswered questions after being diagnosed in connection with screening [32]. Despite the consultation with an experienced vascular surgery specialist 1 - 2 months after the diagnosis, many of the informants complained that they had not received enough information about how quickly their aorta was growing and what could be done to prevent growth. They also had questions concerning restrictions in everyday life and how long the regular check-ups would continue [32]. However, in our study most participants did not experience any form of panic/anxiety in relation to screening.

Even when participants strive to maintain control and do not allow the aneurysm to affect their daily lives, it is still likely that their lives are influenced, as our informants stated that many questions about lifestyle and how to prevent the aneurysm from growing were left unanswered by the healthcare professionals. Prevention is important for health promotion from a public-health perspective. People who smoked at the time of screening had a significantly lower HRQL than non-smokers.

Our results revealed that almost half of the participants sometimes experienced life as sluggish. This finding is based on responses to single questions and does not concern anxiety or depression. The men were included in the screening programme during their 65th year, which is the age of retirement in Sweden. A third of them were still professionally active. For many people, retirement implies a major change in life and this, rather than the result of the screening, may have influenced the HAD scores. However, it is possible that other factors could also have exerted an influence.

Population screening is not uncontroversial. Is it ethical to expose people who believe they are healthy to a process in which they become a "patient" when few will die of the disease, especially as most do not require treatment other than regular check-ups. Berterö et al. [33] revealed that men who were informed that their aorta had grown since the first examination expressed feelings of disappointment and anxiety, believing that their condition would entail restrictions in their daily life. In their study, Pettersson \& Bergbom [34] demonstrated 
that patients were surprised that they had not experienced any symptoms or signs of the aneurysm, causing some to lose faith in their ability to interpret body signals. They felt that they could no longer rely on their body and therefore became apprehensive about their health and well-being.

Few persons had knowledge of AAA before screening and some arrived for the examination with no idea of the type of investigation that would be made. However, a majority were satisfied with the written information provided in connection with the screening. In guidelines for screening in the UK, it is explicitly stated that patients' autonomy must be respected, as well as their right to decide whether or not to undergo any medical investigation. The staff should be careful to clearly explain the purpose of the screening, the likelihood of positive or negative findings and the possibility of false-positive or negative results. "Participants in screening are autonomous consumers of health care who should have access to information to enable informed choice about whether or not to participate" [35]. A telephone call can help the individual to make a decision to undergo screening. Of those who did not turn up because they forgot or wanted more information, a personal conversation might be helpful by explaining the reason for the screening. It is unlikely that those who were too sick or believed that AAA did not affect them would participate, irrespective of phone calls or a personal consultation. The cost of screening and travel distance had no effect on participation, which can be explained by the low cost and the fact that the screening took place close to the subject's home. Caring for these patients means that the nurse must be prepared to listen attentively and inquire about their experiences and those of their family members, as well as their feelings of well-being and need to discuss worries and concerns. Additionally, nurses must take the time to answer questions about the examination, AAA diagnosis and living daily life with an aneurysm. This may make the men feel that they have some influence or control over the examination and, for those with an aneurysm, over their own health. Annual follow-up sessions offer care providers a great opportunity to support the patients' own resources and efforts to maintain a sense of health and well-being.

\subsection{Limitations}

There are some ethical considerations that should be taken into account. The study was based on a rationalist perspective, where 65-year-old men who were considered healthy were investigated. We did not consider women's experiences of the screening procedure, therefore the study only reflects the culture of men who could speak and understand the Swedish language.

The SF-36 is commonly used to measure HRQoL with the general population as a reference. This presents no problem when the subjects are of varying sex and age. However, the fact that our study population only comprised men in their 65th year revealed the weaknesses inherent in the method, as the general population had a high standard deviation. We therefore decided to lower the level of significance to $\mathrm{p}<0.001$ but nevertheless present all p-values.

\subsection{Conclusion}

The men who participated in the investigation were healthier in some SF-36 domains than the matched general population. Statistical differences were seen in all HQoL domains for those who had symptoms compared to those who did not report any symptoms. Persons who smoked also had a lower score in some of the SF-36 domains compared to non-smokers. The patients did not experience any great anxiety/concern about the screening and despite the short duration of the examination were of the opinion that it functioned well.

\subsection{Relevance to Clinical Practice}

More detailed information should be provided about the reason for the screening programme as well as the fact that the procedure itself is quick and simple. Clearer guidelines are required for care in the course of the examination that is adapted to the individual's physical and psychological needs, as well as for informing about the outcome. Some people may need additional information in order to undergo the screening. Caring for these patients means that the nurse must be prepared to listen attentively and inquire about experiences of well-being as well as about their need to discuss worries and concerns about the screening procedure.

\section{Acknowledgements}

The authors are grateful to the patients for participation in the study. 


\section{References}

[1] Heikkinen, M., Salenius, J.P. and Auvinen, O. (2002) Ruptured Abdominal Aortic Aneurysm in a Well-Defined Geographic Area. Journal of Vascular Surgery, 36, 291-296. http://dx.doi.org/10.1067/mva.2002.125479

[2] Brodersen, J., Jorgensen, K.J. and Gotzsche, P.C. (2010) The Benefits and Harms of Screening for Cancer with a Focus on Breast Screening. Polskie Archiwum Medycyny Wewnętrznej, 120, 89-94.

[3] Stewart-Brown, S. and Farmer, A. (1997) Screening Could Seriously Damage Your Health. BMJ, 314, 533-534. http://dx.doi.org/10.1136/bmj.314.7080.533

[4] Ilic, D., Neuberger, M.M., Djulbegovic, M. and Dahm, P. (2013) Screening for Prostate Cancer. Cochrane Database of Systematic Reviews, 1, Article ID: CD004720. http://dx.doi.org/10.1002/14651858.CD004720.pub3

[5] Gotzsche, P.C. and Nielsen, M. (2009) Screening for Breast Cancer with Mammography. Cochrane Database of Systematic Reviews, 4, Article ID: CD001877.

[6] Lindholm, E., Berglund, B., Kewenter, J. and Haglind, E. (1997) Worry Associated with Screening for Colorectal Carcinomas. Scandinavian Journal of Gastroenterology, 32, 238-245. http://dx.doi.org/10.3109/00365529709000201

[7] Lindholdt, J.S., Vammen, S., Fasting, H. and Henneberg, E.W. (2000) Optimal Interval Screening and Surveillance of Abdominal Aortic Aneurysm. European Journal of Vascular and Endovascular Surgery, 20, 369-373. http://dx.doi.org/10.1016/S1078-5884(00)91191-2

[8] Scott, R.A. (1995) Influence of Screening on the Incidence of Ruptured Abdominal Aortic Aneurysm: 5-Year Results of Randomized Controlled Study. British Journal of Surgery, 82, 1066-1070. http://dx.doi.org/10.1002/bjs.1800820821

[9] Edwards, A., Evans, R., Dundon, J., Haigh, S., Hood, K. and Elwyn, G. (2006) Personalised Risk Communication for Informed Decision Making about Taking Screening Tests. Cochrane Database System Review, 4, Article ID: CD001865.

[10] Irwig, L., McCaffery, K., Salkeld, G. and Bossuyt, P. (2006) Informed Choice for Screening: Implications for Evaluation. British Medical Journal, 332, 1148-1150. http://dx.doi.org/10.1136/bmj.332.7550.1148

[11] Ashton, H.A., Buxton, M.J., Day, N.E., Kim, L.G., Marteau, T.M., Scott, R.A., et al. (2002) The Multicenter Aneurysm Screening Study (MASS) into the Effects of Abdominal Aortic Aneurysm Screening on Mortality in Men: A Randomised Controlled Trial. Lancet, 16, 1531-1539.

[12] Cosford, P.A., Leng, G.C. and Thomas, J. (2011) Screening for Abdominal Aortic Aneurysm. Cochrane Database of Systematic Reviews. http://dx.doi.org/10.1002/14651858.CD002945.pub2

[13] Mastracci, T. and Cina, C. (2007) Screening for Abdominal Aortic Aneurysm in Canada Society for Vascular Surgery. Journal of Vascular Surgery, 45, 1268-1276. http://dx.doi.org/10.1016/j.jvs.2007.02.041

[14] Schermerhorn, M., Zwolak, R.,Velazquez, O., Velazques, O., Makaroun, M., Fairman, R., et al. (2008) Ultra Sound Screening for Abdominal Aortic Aneurysm in Medicare Beneficiaries. Annual of Vascular Surgery, 22, 16-24. http://dx.doi.org/10.1016/j.avsg.2007.07.026

[15] Lederle, F.A. (2008) Screening for AAA in the USA. Scandinavian Journal of Surgery, 97, 139-141.

[16] Wanhainen, A., Rosen, C., Rutegard, J., Bergqvist, D. and Bjorck, M. (2004) Low Quality of Life Prior to Screening for Abdominal Aortic Aneurysm: A Possible Risk Factor for Negative Mental Effects. Annuals of Vascular Surgery, 18, 287-293. http://dx.doi.org/10.1007/s10016-004-0021-x

[17] Lindholm, E., Brevinge, H., Bergh, C.H., Korner, U. and Lundholm, K. (2003) Relationships between Self-Reported Health Related Quality of Life and Measures of Standardized Exercise Capacity and Metabolic Efficiency in a MiddleAged and Aged Healthy Population. Quality of Life research, 12, 575-582. http://dx.doi.org/10.1023/A:1025034919526

[18] Lindholt, J.S., Vammen, S., Fasting, H. and Henneberg, E.W. (2000) Psychological Consequences of Screening for Abdominal Aortic Aneurysm and Conservative Treatment of Small Abdominal Aortic Aneurysms. European Journal of Vascular and Endovascular Surgery, 20, 79-83. http://dx.doi.org/10.1053/ejvs.1999.1087

[19] Reventlow, S.D., Hvas, L. and Malterud, K. (2006) Making the Invisible Body Visible. Bone Scans, Osteoporosis and Women’s Bodily Experiences. Social Science \& Medicine, 62, 2720-2731. http://dx.doi.org/10.1016/j.socscimed.2005.11.009

[20] Adelswärd, V. and Sachs, L. (1996) A Nurse in Preventive Work. Dilemmas of Health Information Talks. Scandinavian Journal of Caring Sciences, 10, 45-52. http://dx.doi.org/10.1111/j.1471-6712.1996.tb00309.x

[21] Bengtsson, H. and Bergqvist, D. (1993) Ruptured Abdominal Aortic Aneurysm: A Population-Based Study. Journal of Vascular Surgery, 18, 74-80. http://dx.doi.org/10.1067/mva.1993.42107

[22] Schweikert, B., Hunger, M., Meisinger, C., Konig, H.H., Gapp, O. and Holle, R. (2009) Quality of Life Several Years after Myocardial Infarction: Comparing the MONICA/KORA Registry to the General Population. European Heart Journal, 30, 436-443.

[23] Lupton, D. (1999) Risk. Routledge, London. 
[24] SOU (2000) Hälsa på lika villkor—Nationella mål för folkhälsan. Nationella folkhälsokommittén. 91.

[25] Taft, C., Karlsson, J. and Sullivan, M. (2004) Performance of the Swedish SF-36 Version 2.0. Quality of Life Research, 13, 251-256. http://dx.doi.org/10.1023/B:QURE.0000015290.76254.a5

[26] Ware Jr., J.E. and Sherbourne, C.D. (1992) The MOS 36-Item Short form Health Survey (SF-36): I. Conceptual Framework and Item Selection. Medical Care, 30, 473-483. http://dx.doi.org/10.1097/00005650-199206000-00002

[27] Sullivan, M., Karlsson, J. and Ware, J.E. (1995) The Swedish SF-36 Health Survey-I. Evaluation of Data Quality, Scaling Assumptions, Reliability and Construct Validity across General Populations in Sweden. Social Science \& Medicine, 41, 1349-1158. http://dx.doi.org/10.1016/0277-9536(95)00125-Q

[28] Brazier, J.E., Harper, R., Jones, N.M., O’cathain, A., Thomas, K.J., Usherwood, T. and Westlake, L. (1992) Validating the SF-36 Health Survey Questionnaire: New Outcome Measure for Primary Care. British Medical Journal, 305, 160-164. http://dx.doi.org/10.1136/bmj.305.6846.160

[29] Zigmond, A.S. and Snaith, R.P. (1983) The Hospital Anxiety and Depression Scale. Acta Psychiatrica Scandinavica, 67, 361-370. http://dx.doi.org/10.1111/j.1600-0447.1983.tb09716.x

[30] ICN: Ethical Code of Nursing (2003) Svensk sjuksköterskeförening. International Council of Nurses: Place Jean-Marteau, 3, Geneva.

[31] Eriksson, K. (1994) Theories of Caring as Health: Caring as Healing. D.A. Gant \& Boykin, p3-0. National League for Nursing Press, New York.

[32] Hansson, A., Brodersen, J., Reventlow, S. and Pettersson, M. (2012) Opening Pandora’s Box: The Experiences of Having an Asymptomatic Aortic Aneurysm under Surveillance. Health, Risk \& Society, 14, 341-359. http://dx.doi.org/10.1080/13698575.2012.680953

[33] Berterö, C., Carlsson, P. and Lundgren, F. (2010) Screening for Abdominal Aortic Aneurysm, a One-Year Follow up: An Interview Study. Journal of Vascular Nursing, 28, 97-101. http://dx.doi.org/10.1016/j.jvn.2010.04.001

[34] Pettersson, M. and Bergbom, I. (2012) To Be under Control: A Qualitative Study of Patients Experiences Living with the Diagnosis of Abdominal Aortic Aneurysm. Journal of Cardiovascular Nursing, 28, 387-395.

[35] Raffle, A.E. and Grey, J.A.M. (2007) Screening: Evidence and Practice. Oxford University Press, Oxford. http://dx.doi.org/10.1093/acprof:0so/9780199214495.001.0001 